\title{
ANALYSIS ON THE COMPARATIVE ADVANTAGE AND EXPORT COMPETITIVENESS OF CHINA'S FRUIT PRODUCTS
}

\author{
Jun Chen \\ SHU-UTS SILC Business School, Shanghai University, P.R.China \\ Chao Chen \\ Economic and Management School, Tongji University, P.R.China
}

Dilin Yao

Economic and Management School, Shanghai Maritime University, P.R.China

\begin{abstract}
China is the world's largest producer of fruits. The fruit industry occupies an important position in the national economy. Since 1993, fruit yield volume and orchard area of China have been ranking the first place in the world. The improvement of the export competition of China's fruit products still has a long way to go. The transfer of fruit production advantages into trading advantages is the primary problem faced by Chinese fruit industry. This article aims to analyze the characteristics and the competitive strength of China's fruit export, as well as their influencing factors. This paper also gives a number of policy recommendations to promote fruit exports and enhance international competitiveness in China. The result of this paper will help the readers to have the full understanding about the export advantages of Chinese fruit industry. It also will be helpful for the related bodies to make correct policies.
\end{abstract}

Key words: Comparative advantage; Export competitiveness; China's fruit products

JEL code: M110

\section{Background}

China is the world's largest producer of fruits. The fruit industry occupies an important position in the national economy. Since 1993, fruit yield volume and orchard area of China have been ranking the first place in the world. In 2013, the export volume has reached 3446 Thousand Tons. From the view of varieties of trees, the productions of apples, pears, peaches, plums and persimmons list top five in the world, especially the persimmons and pears. They accounted respectively $71.5 \%$ and $52.9 \%$ of world output. The production of apples and plums also has around $40 \%$ production of total world. Besides, both of the production volume and orchard area of 
oranges, pears, grapes and bananas are rising, which reflects the trend of Chinese fruit still in expansion. China's fruit production plays an important role in the world. But large production volume and orchard area do not equal to the comparative advantage and export competitiveness. In this occasion, based on the long term and wide range survey, this paper aims to analyze the characteristics and international competitiveness status of Chinese fruit industry, as well as gives some recommendations on the improvement of the comparative advantage and export competitiveness of Chinese fruit industry.

\section{Literature review}

Fruit has comparative advantage of export among the industries in China. Lots of scholars pay their attention on the researches of the fruit trade, which are mainly concentrated on two aspects. One aspect is the analysis of China's fruit international competitiveness. In this field, Gao et al. (2012) analyze the international competitiveness of China's seven main species and the overall international competitiveness of fruit industry with comparison advantage index, resulting in that only pear has strong of competition advantage on the international market while other six species of fruits are lack of competition advantage. Jiang (2011) measures the international competitiveness China's fruit industry through building the indicators system of comparative advantage of international competitiveness, and finds that China's apple and pear has international competitiveness, but other exporting products of Chinese fruit industry are weaker compared with the international competitors. Similar to the previous study, $\mathrm{Hu}$ et al. (2008) figures out that the international competitiveness of citrus, banana, grape, orange, and peach in China should be improved. Li (2011) uses the data between 1996 and 2010, calculating the international competitiveness of apple industry in Hebei province in China. He figures out that the international competitiveness of apple industry in Hebei province has comparative advantage in China, but is still quite weak compared with the other countries. Mao and Chen (2011) analyze the international market share and the comparative advantage of international competitiveness of Chinese and world fruit industry, finding that compared with the major fruit exporting countries in the world. China's exports of fresh fruits and dried fruits have no revealed comparative advantage. To improve the comparative advantage, Wei et al. (2010), Han et al. (2008), Hui and Yin (2011) gave recommendations on adjusting and optimizing the export structures, enhancing awareness, improving quality, strengthening inspection and so on. The other aspect of the researches focuses on the analysis of the factors affecting the fruit export trade in China. Based on the trade gravity model, Yang (2011) conducts an empirical study of factors affecting Chinese fruit export trade Chinese exports using panel data of 1992-2010 for fifteen kinds of fruits, finding that import country's GDP, China agricultural output, distance, whether the import country is APEC members, and bilateral real currency have influence on China's fruit export.

Liu et al. (2006) points out that the gradually weakened comparison advantage of 
labor cost, low fruit quality, simple export structure, less export species, and international green trade barriers are the factors which effect China's fruit export trade. Li et al. (2008) think that the tariff barriers and food security regulations in United States, Japan and EU, product conformity standards and certifications, and technical barriers of trade, have a larger impact on the exportation of the Chinese fruit.

The above literatures among the plenty researches shows the comparative advantage of international competitiveness of China's fruit industry and its influential factors, but the Chinese domestic scholars rarely involve fruit of international marketing research on China fruit export trade. This research will analyze the characteristics, the competitive strength, and the influencing factors of China's fruit export. This paper also gives the recommendations on marketing to promote fruit exports and enhance international competitiveness in China.

\section{Characteristics of exportation of Chinese fruit}

3.1. The target international markets of Chinese exporting fruit are relatively homogenous

Exportation of the Chinese fruit market is mainly concentrated in the United States, Japan, Russia, Indonesia, Germany, Netherlands and other countries, especially the United States, and Japan and Russia countries. In 2013, the exportation of the Chinese fruit to United States, Japan, and Russia has reached 658,295 t, 421,290 t, and $370,278 \mathrm{t}$, which respectively accounts $15.04 \%, 10.57 \%$ and $11.23 \%$ of China's total export volume. These three countries accounted for $36.94 \%$ of China's total export volume. It is visible that fruit exported to international markets in China are quite concentrated.

\subsection{The fruit export provinces are relatively concentrated}

Fruits exporting provinces in China are mainly concentrated in Shandong, Shaanxi, Zhejiang, Guangdong, Fujian and other provinces. In 2013, the five provincial fruit exports amount lists \$ 665 million, \$ 245 million, \$ 195 million, \$ 183 million and $\$ 159$ million, which respectively accounted $35.76 \%, 12.12 \%, 11.39 \%, 9.57 \%$ and $8.34 \%$ of the total amount of exports. This shows that the comparative advantage of international competitiveness of the fruit industry in each province is quite different from each other.

\subsection{The exporting species of Chinese fruit are relatively limited}

According to customs statistics, China exported fruit varieties are mainly concentrated in apple, tangerine, orange, pear, apricot, plum and dried fruits (including pine nuts, walnuts, and chestnuts and so on). In 2013, the exports volume of fresh apples is $991,300 \mathrm{t}$, which is accounting for $51.94 \%$ of the total exports of fresh and frozen 
fruits, and $25.43 \%$ per cent of total fruit exports. This shows that the fruit export species in China is still quite limited.

\subsection{The fruit production is growing fast, but the export rate is still low}

In the past year of 2013, China exported fruits 5.12 million t, which is $13.25 \%$ higher than 2012. Despite China's fruit exports being growing fast, the fruit exports share of production is still low. In 2013, the fruit exports rate is still less than 4\%. This indicates that although China is the world largest producer of fruits, it is still not trading power of fruit in the world.

3.5 The exports of fresh and frozen fruits are higher; the processed agricultural product export is still quite low

In 2013, China's exports of fresh and frozen fruits 3.19 million t, accounting for $56.38 \%$ of the total fruit for export. Fruit processed products such as fruit juice, canned fruit and other processed fruit export still accounts for less than $20 \%$ of total exports. It can be seen that Chinese fruits are dominated by fresh fruit exports; processed agricultural product export is still very low.

\section{The analysis of the comparative advantages of China's fruit industry}

Revealed Comparative Advantage Index (RCA) is firstly proposed by Balassa (1965). RCA is employed as the indicator of export competitiveness (Wang, 2006). RCA formula reflects the relative comparative advantages of countries as follows:

$$
R C A_{i j}=\frac{X_{i j}^{k} / \sum_{i} X_{i j}^{k}}{\sum_{j} X_{i j}^{k} / \sum_{i} \sum_{j} X_{i j}^{k}}
$$

In the above formula, $\mathrm{X}_{i j}^{k}$ refers to the exporting amount of Industry I of Country $\mathrm{j}$ to Area $\mathrm{k}, \quad \sum_{i} X_{i j}^{k}$ refers to the total export of Country $\mathrm{j}, \sum_{j} X_{i j}^{k}$ refers to the total exporting volume of Industry i of Area k to each country.

Theoretically, when RCA is greater than 1, the industry has a comparative advantage of the country, which expresses the industry has relatively stronger ability to compete around the world. Generally, the scholars agree that when RCA is greater than 1, the industry has a comparative advantage (Mao and Feng, 2007). The RCA of the major exporting species of Chinese fruit industry is as following Table 1. From this table, this paper finds that among the seven species of the major exporting fruits in China, the RCA of pear and apple is larger than one. This shows that pear and apple produced in China has strong competitive advantages. Citrus and orange has weak competitive 
advantages. The RCA of banana, grape and peach indicated that they have even weaker competitive advantages. This research conclusion can be also confirmed by the standard of RSCA in Table 2.

Table 1. The RCA of the seven major exporting species of Chinese fruit industry

\begin{tabular}{|l|l|l|l|l|l|l|l|}
\hline Year & Pear & Apple & Citrus & Orange & Banana & Grape & Peach \\
\hline 2004 & 1.27 & 0.97 & 0.28 & 0.15 & 0.02 & 0.01 & 0.03 \\
\hline 2005 & 1.31 & 1.31 & 0.30 & 0.17 & 0.07 & 0.03 & 0.02 \\
\hline 2006 & 1.40 & 1.35 & 0.31 & 0.21 & 0.06 & 0.02 & 0.03 \\
\hline 2007 & 1.45 & 1.26 & 0.29 & 0.22 & 0.09 & 0.04 & 0.04 \\
\hline 2008 & 1.59 & 1.36 & 0.32 & 0.24 & 0.12 & 0.06 & 0.06 \\
\hline 2009 & 1.56 & 1.41 & 0.33 & 0.25 & 0.15 & 0.08 & 0.05 \\
\hline 2010 & 1.61 & 1.38 & 0.35 & 0.26 & 0.19 & 0.09 & 0.06 \\
\hline 2011 & 1.87 & 1.40 & 0.38 & 0.28 & 0.21 & 0.10 & 0.07 \\
\hline 2012 & 1.96 & 1.42 & 0.41 & 0.29 & 0.23 & 0.12 & 0.07 \\
\hline 2013 & 1.98 & 1.49 & 0.42 & 0.31 & 0.26 & 0.16 & 0.08 \\
\hline 2014 & 1.00 & 1.09 & 0.72 & 0.19 & 0.00 & 0.36 & 0.29 \\
\hline 2015 & 1.28 & 1.06 & 0.72 & 0.13 & 0.01 & 0.71 & 0.40 \\
\hline 2016 & 1.54 & 1.42 & 0.70 & 0.18 & 0.01 & 0.63 & 0.35 \\
\hline
\end{tabular}

Data Source: Calculated Based on UN Comtrade Database • •

Table 2. The standard of RSCA in this research

\begin{tabular}{|l|l|l|l|}
\hline $\begin{array}{l}\text { The degree of competitive } \\
\text { advantages }\end{array}$ & RCA & Data range & RSCA \\
\hline Quite strong & Larger than 2.5 & Larger than 0.43 & $\begin{array}{l}\text { This industry has quiet } \\
\text { strong competitive } \\
\text { advantages }\end{array}$ \\
\hline Strong & $1.25 ~ 2.5$ & $0.11-0.43$ & $\begin{array}{l}\text { This industry has strong } \\
\text { competitive advantages }\end{array}$ \\
\hline Medium & $0.8 \sim 1.25$ & $-0.11-0.11$ & $\begin{array}{l}\text { This industry has medium } \\
\text { competitive advantages }\end{array}$ \\
\hline Weak & Smaller than 0.8 & Smaller than -0.11 & $\begin{array}{l}\text { This industry has weak } \\
\text { competitive advantages }\end{array}$ \\
\hline
\end{tabular}

In Table 2, RSCA was shown as a new index. As the range of RCA index can be from zero to infinite that cannot well reflect the change of trade pattern in terms of measuring advantages and disadvantages. In this occasion, RSCA was put forth as an index to measure the comparative advantage of Chinese fruit industry (Pratten, 1971). The larger value of RSCA shows that the competitive advantages of the industry in the country are stronger (Porter, 1990). This research employed the following formula: 
$R S C A_{i j}=\left(R C A_{i j}-1\right) /\left(R C A_{i j}+1\right)$

$R S C A_{f r}=\beta_{0}+\beta_{1} E_{f t}+\beta_{2} P_{f t}+\beta_{3} I_{f t}+\beta_{4} R D_{f t}+\varepsilon_{f t}$

$R S C A_{f r}$ refers to the competitive advantages of the industry in the country; $E_{f t}$ refers to the exporting volume of the industry in the country; $P_{f t}$ refers to the unit price of exporting of the industry in the country; $I_{f t}$ refers to the investment of the industry in the country; $R D_{f t}$ refers to the research and development index of the industry in the country (Leamer, 1993).

\section{Analysis of factors affecting international competitiveness of Chinese fruits}

5.1. Low costs make Chinese fruit have a relative price advantage internationally, but the advantage has been gradually weakened.

Prices are basic factors affecting international competitiveness. In the same market area, for the identical or similar products, the lower price yields stronger competitiveness, but prices are significantly influenced by cost. Costs include the production cost, circulation costs and tax costs. Cost of production is the foundation, including the production of machinery, raw material costs and labor costs. China's fruit production is labor intensive industries, so the labor costs are lower. In 2013, the average sale price of apples, oranges and tangerines these types of fruit is not more than 2 Yuan per KG. In addition, production costs accounted for a larger proportion. China has lower production costs, which are important causes of the lower price of fruits in China. From the view of net income, the Chinese pure fruit costs is yielding a declining trend in the world, which shows that China's cost advantage is being gradually weakened.

5.2. The fruit quality is the key factor affecting international competitiveness of Chinese fruits.

First of all, the factor of quality appearance is an important factor affecting the exportation of the Chinese fruit. North China has deep soil layer, high altitude, with greater temperature difference between day and night. This is one of the best suitable planting areas in the world recognized by both Chinese and foreign experts. Apple produced here has the bigger size, fresh color, sweet and sour taste. It is comparable to Washington State apples in the United States and loved by the foreign consumers. But the appearance of the fruit quality is poor, and this becomes the major shortcoming of the apple export in this area. Secondly, the fruit storage and fresh-keeping technology is the limitation for Chinese fruit export. The storage is a systematic work, which includes cooling, refrigeration, insulated transport, and entry into the consumer market. This is the complete cold chain system. $90 \%$ of fruit in Japan has been through a cold treatment. While in China, pre-cooling technology 
usage is only 5\%. Moreover, the cold chain transport for most of the fruit is not yet available in China, and the fruit storage with cold chain transport is only $10 \%$. In addition, fruit machines for fruits started late in China with fast development, but do not form a scale levels. The fruit in western countries can be stored in a timely manner, and $70 \%-80 \%$ has been controlled with atmosphere storage. But the storage capability of China's fruit production is only $20 \%$, and mostly with easy storage, refrigeration, modified atmosphere storage. Thirdly, the commercial treatment capacity factor is another shortcoming of Chinese fruit industry. The fruit postharvest handling is the value-adding processing after harvesting, including selection, grading, and washing, waxing, ripening and packing process. At present, over $90 \%$ fruit in European countries has postharvest treatment, but it is less than $40 \%$ in China. Despite the greater improvement in recent years, it still has a wide gap with the western countries. Some fruit growers and distributors do not wash and wax the fruit, which seriously affected the export of fruit.

5.3. The single fruits structure is an important factor affecting the export competitiveness of Chinese fruits.

The development of China's fruit industry has more than 20 years, both in terms of structure and regional distribution has made certain achievements, but compared with the structural changes in consumer demand in the international market, China's fruit production structure also has significant flaws. Firstly, three varieties of apples, oranges and pears still account for a large proportion, but high valued products' proportion is still very low. Secondly, the concentration of fruit maturity period is another problem. Fruit maturity are more concentrated, but the storage, further processing techniques and marketing concepts is quite backward, making fruit sales influenced by short-term market fluctuations. This often results in substantial backlog of rotting fruit in the short term. Thirdly, mixtures of varieties of fresh and processed are not proper. Apple juice, frozen fruit, and canned class have become the best-selling product on the international market, and production of fruit varieties in China is mainly suitable for fresh food. In this occasion, very few specialized fruit varieties for processing top grade fruit juice. The fruit juice category has become less restricted export problems.

5.4. The international Green trade barrier is the presence of external factors affecting international competitiveness of Chinese fruits.

The harsh fruit testing standard in recent years has been developed into a number of mandatory standards in developed countries, such as organic phosphorus, organic chlorine pesticide residues, and so on. These countries use their high-tech and precision testing equipment for precision analysis with harsh standards. United States is one of main export markets of Litchi in Guangdong province. The inspection and quarantine in United States require that the fruit should not have any insects and leaves, and not be exceeding $10 \mathrm{~cm}$, and so on. These demanding requirements have 
very large impact on Guangdong's lychee exports. Japan announces its "positive list system" for the agricultural chemicals in food on May 29, 2006, which has developed criteria on all agricultural chemicals in food (pesticides, veterinary drugs, additives), enabling the management of all agricultural chemicals. This largely restricts Chinese tropical fruit from entering Japan market. This shows that there are many problems in current pesticide residue limits in tropical fruits in China, including less accompanying testing methods; there is no residue or domestic use of pesticides for not registered producers, and so on.

\section{Policy recommendations on the improvement of international competitiveness of Chinese fruits}

\subsection{The establishment of fruit quality standard and quality control system.}

The strict technical standards and management standards of production and implementation of brand strategy are the important methods addressing current issues, such as fruit sales difficulties and increasing production without increasing profits. With the accelerated international trade integration process, the establishment of the international standards of fruit has become an inevitable trend of quality standard system. These criteria include fruits and processed product quality standard system frame construction; the formulation, revision and improvement of product quality standards, the preparation and revision of the technical specification for production or processing, and the research and development and revision, and so on.

\subsection{Actively explore the international fruit market.}

In future, on the premise of strengthening the market share, Chinese fruit industry should actively explore markets such as North America, Europe, South America, and Africa, and so on. The fruit export market diversification should avoid dependence on the single market in order to reduce fruit operation risks and increase fruit production and trade profits. The exploration of the overseas market should pay much attention on the local culture, taste and consumer behavior. Chinese fruit producers and traders should take careful marketing researches overseas and use internet and useful market tools.

6.3. Take full advantage of the domestic support and regulation space provided by WTO agricultural agreement to enhance the regulation intensity levels.

Government should strengthen the research and forecasting of the demand for fruit market through increasing technology inputs and promotion of fruit new species, enhancing the protection to production, improving the cultivation technology, irrigation technology, and pest control, and so on.

\subsection{Promote fruit new species.}


The research and marketing departments should actively introduce and cultivate good marketable fruit varieties, adjust the structure of fruit varieties, improve layouts of good varieties, establish seed breeding bases of fruit varieties, and meet the needs of farmers. Adjustment of fruit variety and layout for the international market should conduct the careful investigation of the supply and demand on the international market, as well as understand the resources and fruit production costs, international enterprise scale, production capacity and product quality of the fruit industry in the foreign fruit producing area. Chinese fruit industry should have a more comprehensive understanding about the international competitors in order to improve the international competitiveness of Chinese fruits.

\subsection{Take efforts to improve fruit production technology.}

Improve the product quality and take control of the production through the washing, bagging, and other advanced technologies in accordance with international safety requirements of high quality fruit products. Advanced technology is the guarantee of production of high quality fruit, so China must introduce advanced management of fruit production and programming technical management. The improvement of fruit quality is built on a solid foundation of China based on advanced technology. Producing high quality fruit must pay attention to the various techniques and take the usage of advanced technologies, strengthening of technical consulting and technical services for farmers.

\subsection{Accelerate the development of fruit processing industry.}

First of all, Chinese fruit industry is to increase the productivity of existing equipment and production capacity and the production quality of fruit base. Secondly, Chinese fruit industry should intense fruit deep processing and comprehensive utilization technology to improve the competitiveness in the international market. Chinese fruit producers should focus on the development of storage and fruit processing technologies of fresh fruit, fruit juice concentrates, fruit juice drinks, jelly, jam, etc.

\section{Conclusion}

Above all, this article analyzes the characteristics and the competitive strength of China's fruit export, as well as their influencing factors. The result of this paper helps the reader to have the further understanding about the characteristics, the competitive strength, and the influencing factors of China's fruit export. It also can be helpful for the related governmental bodies and following researches. It can be seen that in the future, some of the factors which limit the quality and quantity of Chinese fruit export can be improved. The following researches can focus on the new situation. On the other hand, this research uses RSCA to measure the competitive strength of China's fruit export. Apple and pears are the most competitive fruits for exportation in China. Therefore deciduous fruits will be more competitive for exportation than acid fruits 
and tropical fruits. The future studies can be combined with the other indexes to conduct the comparison, such as make full use of the supply chain network to achieve global production and make full use of cross border E-commerce business model to increase fresh fruits exportation through cold chain logistics. Furthermore, from 2014, China Importation and Exportation have entered into new era of cross border E-commerce. Fruits exportations witness the new distribution channel to increase the competitiveness by avail of the overseas warehouses at the destination countries. The author will continue to do the research in cross border E-commerce as well as the opportunities offered on the project of Belt and Road.

\section{Reference}

Balassa, B. (1965) "Trade Liberalization and 'Revealed' Comparative Advantage", The Manchester School of Economic and Social Studies, vol. 33, no.2, pp. 99-123.

Gao, Z. Q., Zhao, C. X., Cheng, J. J. and Zhang, X. C. (2012) “Tree structure and 3-D distribution of radiation in canopy of apple trees with different canopy structures in China", Chinese Journal of Eco-Agriculture, vol.20, no.1, pp. 63-68.

Han, M. Y., Li, Y. W., Fan, C. H. and Zhao, C. P. (2008) "Effects of Branch Bending Angle on Physiological Characteristics and Fruit Quality of Fuji Apple", Acta Horticulturae Sinica, vol. 35, no.9, pp. 1345-1350.

Hu, X. S., Hong, W. and Wu, C. Z. (2008) "Prediction model of cultivated land in Fujian Province based on BP neural network", Journal of Fujian Agriculture and Forestry University (Natural Science Edition), vol. 37, no. 4, 425-427.

Hui, X. J. and Yin, C. W. (2011) "Study on Agricultural Water in Shaanxi Province Based on Uncertainty Gray Prediction", Journal of Anhui Agricultural Sciences, vol. 39, no.6, pp. 3161-3162.

Jiang, T. (2011) "The Research on the Status of Small-and-Medium-Sized Enterprises of County in the Dominant Industry of Shaanxi County Economy", Journal of Anhui Agricultural Sciences, vol.39., no.2, pp. 1166-1168+1171.

Leamer, E. (1993) "Factor-Supply Differences as a source of comparative advantage", The American Economic Review, vol. 83, no. 2, pp. 436-439.

Li, J. R., Zou, Y. J and Ren, X. L. (2008) "Humble opinion about modern apple industry in China”, Journal of Fruit Science, vol.25, no.3, pp. 378-381.

Li, X. S. (2011) "Development and Suggestions of Apple Industry in Hebei Province", Journal of Hebei Agricultural Sciences, vol.15, no.3, pp. 130-132. 
Liu, F. Z., Wang, K., Cao, Y. F., Gao, Y. and Gong, X. (2006) "Advances and prospect in research on apple germplasm resources in China", Journal of Fruit Science, vol.23, no.6, pp. 865-870.

Mao, F. X. and Chen, Z. Q. (2011) "An empirical analysis on international competitiveness of fruit industry in Shaanxi Province", Journal of Xi'an University of Posts and Telecommunications, vol.16, no. 4, pp. 96-100.

Mao, F. X. and Feng, Z. X. (2007) "On the Competitiveness of China's Agricultural Product under New Trade Structure”, Journal of International Trade, vol. 33, no. 6, pp. 45-49.

Porter, M. E. (1990) The Competitive Advantage of Nations, New York: The Free Press.

Pratten, C. F. (1971) Economies of Scale in Manufacturing Industry, Cambridge: Cambridge University Press.

Wang, X. P. (2006) "Commentary of the Diamond Theory Model”, Journal of Tianjin University of Commerce, vol.26, no.2, pp. 33-36+70.

Wei, N., Bian, K. J. and Yuan, Z. F. (2010) "Analysis and Forecast of Shaanxi GDP Based on the ARIMA Model", Journal of Anhui Agricultural Sciences, vol. 38, no. 9, pp. 4933-4935.

Yang, M. R. (2011) "An Investigation and Study on Information Needs and Service of Fruit Industry from the Perspective of Fruit Farmers", Journal of Anhui Agricultural Sciences, vol. 39, no.12, pp. 7455-7456+7459. 